\title{
A Semantic Recommendation System for Learning Personalization in Massive Open Online Courses
}

\author{
https://doi.org/10.3991/ijes.v8i1.14229 \\ Assami Sara $(\bowtie)$ \\ ENSIAS, Mohammed V University, Rabat, Morocco \\ saraassami@gmail.com \\ Daoudi Najima \\ Information Sciences School (ESI), Rabat, Morocco \\ Ajhoun Rachida \\ ENSIAS, Mohammed V University, Rabat, Morocco
}

\begin{abstract}
For an innovation producing education, MOOC (Massive Open Online Course) platforms offer a plethora of learning resources and pedagogical activities to support the university's 4.0 new era and the lifelong learning movement. Nevertheless, the rapid advances in learning technologies imply the need for personalized guidance for learners and adapted learning materials. In this paper we seek to enhance the MOOC learner experience by providing a semantic recommender system for the diversity and abundance of MOOCs available for learners. Firstly, the paper analyses the state of the art of the semantic recommendation approach in a distance learning context. Then it describes the proposed MOOC recommendation system that uses the ontological representation of the learner model and MOOCs content to make its intelligent suggestions. Finally, we explore the development phases of the semantic MOOC recommendation system to define the implications for the progress of our research.
\end{abstract}

Keywords-Distance learning, Massive Open Online Course, recommendation system, Knowledge-based recommendation

\section{Introduction}

Seeking an intuitive experience in online learning has become the new trend in lifelong learning platforms like MOOC platforms by exploiting the plethora of possibilities offered by artificial intelligence. In this context, the university 4.0 uses artificial intelligence for a better understanding of learning needs by learning analytics tools; and monitoring of learners' progress by using adaptive learning toolkits. However, the key to the success of such tools is to keep the openness of learning platforms and introduce personalization principles that consider the learner's characteristics. As a result, we shed the light on recommender systems for an enhanced learner experience to support the exploration of different MOOCs offered by different platforms. 
A recommender system compares the user profile with features of reference and seeks to predict the potential opinion of a user about an item [1]. However, in a distance learning context : "different learners have different characteristics in terms of learners' background knowledge, learners' history, competence level, learning style and learning activities [2]. This makes "recommendation of learning resources to a particular learner more difficult" [3]. The issue is more observed in MOOC platforms where it becomes difficult to predict the learner's interests with the massive dimension of MOOCs: a variety of learner's profiles and a difficult understanding of factors influencing their motivation and engagement for specific online courses. "This complexity in recommendation of learning resources can be alleviated by personalizing the learner profile to match the needs and characteristics of the learner by using knowledge structures such as ontology" [3]. For this purpose, we discuss in the second section the knowledgebased recommender system features for the distance learning "to suggest adequate MOOCs for specific learner models". As for the third section, we design the functional architecture of our proposed RS for MOOCs, the use cases of its main actors: the learner and the MOOC provider, and finally: the development phases of our ongoing research.

\section{Recommender systems for a distance learning context}

In general, on the classification issue of recommender systems, [4] states that recommenders can be classified according to the obtained knowledge on its users, their relations to other users, the items to recommend and finally the classes of items that we could identify.

For the filtering approaches used in distance learning, we could identify three RS types: content based, collaborative based and hybrid based since most of literature review research on recommenders in e-learning "focus on these conventional recommendation techniques" [3]. Nevertheless, the e-learning context requires a recommendation approach that favors concepts semantic relationships and that is sensible to the learner preference and needs updates. In this sense, knowledge- based recommender systems "use prior knowledge on how the recommended items fulfill the user needs. Thus, the goal of a knowledge-based RS is to reason about the relationship between a need and a possible recommendation" [5]. What's more is that it favors knowledge reuse and sharing: one of the main principles of online learning.

\subsection{The Knowledge based approach}

First of all, knowledge-based (KB) recommenders match between the user needs and the items features .So, it suggests items based on logical inferences on the preferences and needs of the user [6] [7]. The recommendation is done by using the acquired domain knowledge that the system compares to the user requirements to obtain the most adequate and useful items for a specific user [1], [8].

"Knowledge based systems are based on the concept "Tell me what fits my needs" [8]. Hence, "this knowledge will sometimes contain explicit functional knowledge about how certain product features meet user needs" [7], like when an e-commerce 
platform asks its clients to choose specific features about their preferences for available products.

Above all, KB recommenders rely on a knowledge base for users, for items and for the matching inference rules in order to recommend the appropriate items for the right users. Obviously they would require knowledge engineering techniques [3] for their development but most importantly they introduce the semantic dimension to the recommendation process unlike other recommendation techniques that rely on the user's ratings for items.

As a knowledge-based framework for recommendation, ontologies introduce the semantic web technologies and go beyond "the most, used definition in the field of computer science: Ontology is a formal, explicit specification of a shared conceptualization ..." [9]. Indeed, it offers the possibility of integrating a frame of inference rules for personalized recommendation by using the semantics principles and interoperability between multiple platforms. As a result, it enables "reusing and sharing knowledge across a wide range of systems" [10].

On the whole, Ontology-based (OB) recommenders are knowledge-based recommender systems which use an "ontology to represent knowledge about the items and users in the recommendation process" [3]. Indeed, "the semantic relations between ontology concepts allow making inferences on this source of knowledge and preference expansions that help to mitigate the effect of sparsity and cold-start problems" [11].

\subsection{Semantic recommender systems for distance learning}

Semantic recommender systems are based on "is-a" relationships by using the semantic links as a similarity measure between concepts which improves the recommendation precision and reduces the disadvantages of new items' recommendation. Particularly in e-learning, "ontology-based recommender systems use ontology knowledge about the learner and learning resources in mapping a learner to relevant learning resources" [3].

However, there are no semantic relationships among courses in current MOOC (Massive Open Online Courses) platforms [12], which are supposed to establish an offer of distance learning to the masses. Ref. [12] adds that the MOOC interfaces "are more similar to the traditional digital library where searching for a specific resource would involve the process of finding an appropriate course among the listed categories of courses" [12].

Consequently, there was "no survey... carried out on ontology-based recommender systems for e-learning" except for Ref. [3]'s review who gave a detailed insight on Ontology based recommenders from the published related research between 2005 and 2014.

To study the use of semantic recommenders, we select from literature work the recommender systems that use semantics to represent both learners and learning. Hence, Table 1 summaries the research of seven papers by defining their "semantic recommender system", "the recommendation approach" to show the role of semantics; and the "ontology use" to specify its modeling purposes. 
Paper-A Semantic Recommendation System for Learning Personalization in Massive Open Online...

Table 1. Semantic recommender systems and ontology use for distance learning

\begin{tabular}{|c|c|c|c|}
\hline Ref. & $\begin{array}{c}\text { Semantic recommender } \\
\text { system }\end{array}$ & Recommendation approach & Ontology use \\
\hline$[13]$ & $\begin{array}{l}\text { Semantic recommendation } \\
\text { of content for context-aware } \\
\text { e-learning where the recom- } \\
\text { mender uses knowledge } \\
\text { about the learner, the content } \\
\text { and the domain of learning. }\end{array}$ & $\begin{array}{l}\text { Recommendation approach in four } \\
\text { steps: "semantic relevance calculation, } \\
\text { recommendation refining, learning path } \\
\text { generation and recommendation aug- } \\
\text { mentation ». }\end{array}$ & $\begin{array}{l}\text { Domain ontologies used } \\
\text { for knowledge modeling } \\
\text { (learner ontology, con- } \\
\text { tent ontology and com- } \\
\text { puter science ontology) }\end{array}$ \\
\hline$[14]$ & $\begin{array}{l}\text { A System for personalized } \\
\text { search and delivery of learn- } \\
\text { ing objects to learners } \\
\text { (PSDLO) }\end{array}$ & $\begin{array}{l}\text { Recommends by a comparison of the } \\
\text { learner profile and the learning object } \\
\text { description repository on the web. }\end{array}$ & $\begin{array}{l}\text { Ontological models for } \\
\text { learners and learning ob- } \\
\text { jects based on the stand- } \\
\text { ards LOM and IMS LIP }\end{array}$ \\
\hline [15] & $\begin{array}{l}\text { Ontology driven recom- } \\
\text { mender system with vector- } \\
\text { based similarity measures. }\end{array}$ & $\begin{array}{l}\text { Documents recommendation for learners } \\
\text { to students according to their current ac- } \\
\text { tivity that is tracked in terms of seman- } \\
\text { tic annotations associated to the ac- } \\
\text { cessed resources. }\end{array}$ & $\begin{array}{l}\text { A domain ontology is } \\
\text { constructed from the } \\
\text { modeling of the learner } \\
\text { interests deduced from } \\
\text { his activities. }\end{array}$ \\
\hline$[16]$ & $\begin{array}{l}\text { Personalized recommenda- } \\
\text { tion of learning paths, learn- } \\
\text { ing contents and learning ex- } \\
\text { periences. }\end{array}$ & $\begin{array}{l}\text { A three step approach: } \\
\text { With Learning paths generation by us- } \\
\text { ing semantic inference in the course and } \\
\text { personalized learning contents recom- } \\
\text { mended by matching between learner's } \\
\text { features and learning object ontology. }\end{array}$ & $\begin{array}{l}\text { Domain ontologies for } \\
\text { learners, learning objects } \\
\text { and courses. }\end{array}$ \\
\hline$[17]$ & $\begin{array}{l}\text { A knowledge based person- } \\
\text { alized e-learning recommen- } \\
\text { dation system }\end{array}$ & $\begin{array}{l}\text { Recommendation employment of a ped- } \\
\text { agogy pattern to recommend according } \\
\text { to the prerequisites of the learner request } \\
\text { and learner's knowledge. }\end{array}$ & $\begin{array}{l}\text { A common domain on- } \\
\text { tology for the learner and } \\
\text { learning materials }\end{array}$ \\
\hline $\begin{array}{l}{[18],} \\
{[19]}\end{array}$ & $\begin{array}{l}\text { "LORecommendNet", a } \\
\text { multi agent-based learning } \\
\text { object recommendation sys- } \\
\text { tem }\end{array}$ & $\begin{array}{l}\text { Use of feature-based recommendation } \\
\text { algorithm to recommend "learning ob- } \\
\text { ject to learners based on their learning } \\
\text { style » [18]. }\end{array}$ & $\begin{array}{l}\text { uses ontology to repre- } \\
\text { sent knowledge about } \\
\text { learning objects, learner } \\
\text { model and semantic } \\
\text { mapping rules. [19] }\end{array}$ \\
\hline$[20]$ & $\begin{array}{l}\text { A hybrid knowledge-based } \\
\text { system for recommendation } \\
\text { of e-learning resources }\end{array}$ & $\begin{array}{l}\text { A four steps recommendation approach } \\
\text { that relies on ontology and sequential } \\
\text { pattern mining (SPM). }\end{array}$ & $\begin{array}{l}\text { Domain ontologies for } \\
\text { the learner profile and } \\
\text { learning resources for } \\
\text { computing the similarity } \\
\text { of learning objects and } \\
\text { their ratings by learners. }\end{array}$ \\
\hline
\end{tabular}

\section{A Proposed recommender system for MOOC Personalized Learning}

In this section, we set the MOOC recommendation system framework of development that is not only limited to its functional architecture but also requires a global view on its use cases, its data sources and the processing of obtained information to make an intelligent feedback for learners. The primary development choices for our knowledgebased recommender are exposed for a better system specification definition. 


\subsection{The MOOC recommender system framework of development}

According to the adapted framework for the analysis of recommender systems of [6], our MOOC recommender system has the following features:

1. finding novel items and useful resources: the recommender tries to find suitable items, e.g. MOOCs, that could answer the learner's needs and preferences;

2. modeling users by using semantics: the chosen representation for the user model is a derived ontology from the domain ontology manually created for recommendation purposes. It represents the learner as a group of knowledge concepts and personal characteristics ;

3. extracting user's and items description manually and/or by using machine learning techniques: the recommender uses the provided data by learners about their interests and by MOOC providers about their courses. It also exploits the navigation history of learners to deduce their characteristics and specific fields of interest;

4. providing personalized recommendations: the suggestions of MOOCs for learners are the predicted useful items obtained by calculating the semantic similarity between learners and MOOCs. Learners and MOOCs are each represented by a vector in the vector space based on the ontological model developed in the diagnosis phase;

5. imbedding recommendations in the user's experience: the recommender system is located at one particular location but uses the aggregated databases of MOOC platforms and learner's profiles. It provides recommendation from a separate entity from the MOOC platform since it uses external data sources. Further, it acts on a passive mode: it produces recommendations as a service for MOOC learners, as soon as they visit a MOOC platform.

The recommender system use cases. A use case diagram is a theorized model that is action oriented and that serves as a support for the requested functionalities of a system. Therefore, we created the use case diagrams for the two main actors of our system: "the learner" that uses the recommender system before; during and after completing a MOOC; and the "MOOC provider", that develops the related metadata for MOOC contents. Consequently, we used the Papyrus software, integrated into the Eclipse development environment (version: Photon R) in UML 2.5 version for both use case diagrams as designed in figure 1 for the intended functionalities to guide the learner, and in figure 2 for the offered functionalities for the MOOC provider, as an important partner for data collection about MOOCs.

The learner needs to:

- authenticate to an e-learning system;

- search for MOOCs according to his interests and/or needs;

- have a list of recommended MOOCs (likely to be of interest);

- have a general profile containing information related to his online learning activities from several MOOC platforms. 


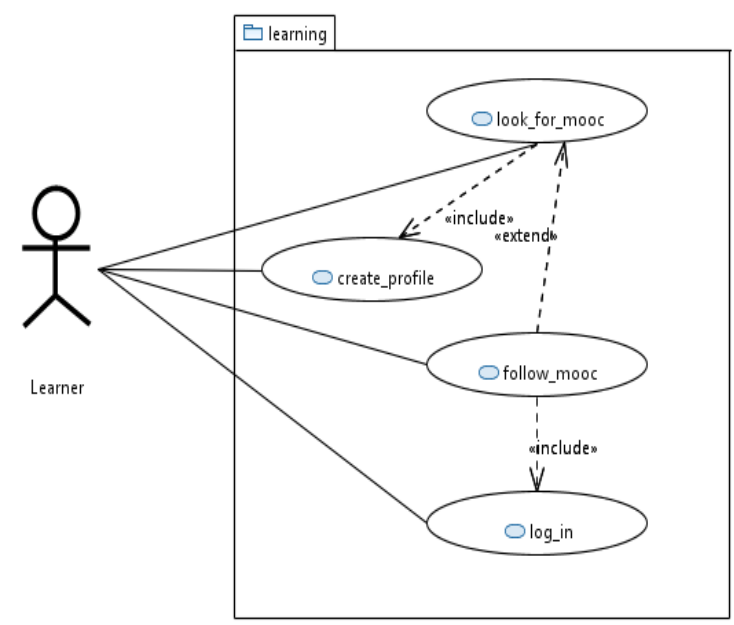

Fig. 1. Learner use case diagram



Fig. 2. MOOC use case diagram

The MOOC provider needs to:

- access services that allow him to be a main partner of our recommender system;

- be able to update the metadata of his MOOC offer and have a global vision of its presence in our system;

- increase the subscription and completion rate of his MOOCs and their indexing on more global search engines.

The recommender system functional architecture. In order to satisfy its requirements (e.g.: predefined uses cases), our recommender engine (figure 3) uses two main components as data sources: "the MOOC meta data extraction tool" and the "the learner 
data extraction tool". On the one hand, the former provides a detailed description of a MOOC's content and other characteristics such as: the language, the learning styles, the workloads needed for completion, etc. It indexes MOOCs that are available in a platform for data retrieval, selection and recommendation of MOOCs. The structured data is stored in aggregate oriented Data Bases (DB) since it gathers all the descriptive information about MOOCs from different platforms. On the other hand, the latter extracts all the personal and learning activity related information about a learner from multiple sources to get a user model that describes the best a learner's interests.

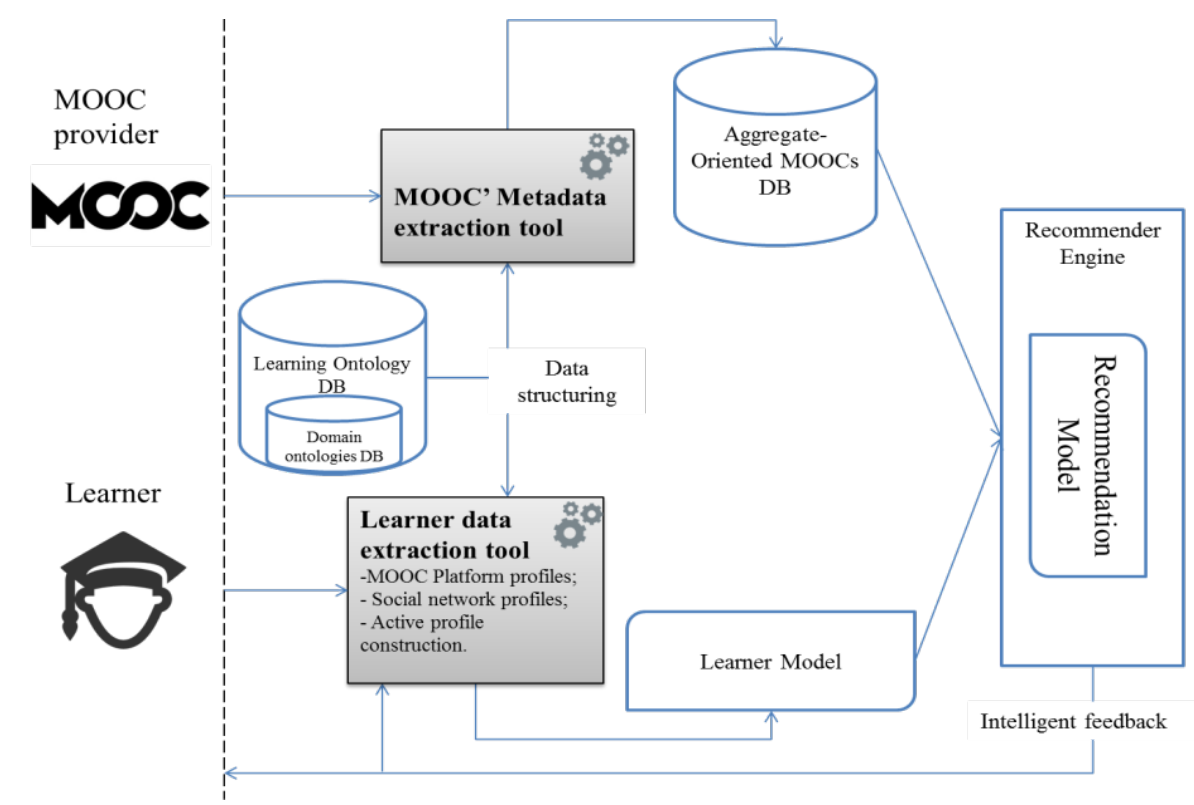

Fig. 3. Functional architecture of personalized suggestions in MOOCs

\subsection{The recommender development phases: a state of our research}

Following the recommender system functional architecture (figure 3), we've been working on the development phases of the recommender engine by addressing the related issues to each of the three phases of the development process: Data collection phase, Learner model generation phase and the Recommender Suggestions' generation phase.

Data collection phase. The data collection's phase aims to generate the learner model by gathering relevant information about the learner's interests and needs. As shown by the functional architecture in Figure 3, we use multiple resources to generate the learner model.

Firstly, the data collection input is based on a hybrid feedback [21] where we consider the explicit feedback of the learner (learner preferences expression on MOOC platforms) and also his implicit feedback (learner search history and behavior on MOOC platforms). Secondly, the learner profile on the MOOC platform provides his 
demographic data and navigation history. We have studied the learner profiles on famous MOOC platforms to deduce the gathered data by MOOC providers. This study's result helped us to define the learner profile attributes to use for the recommendation process. Finally, the social networks data mining helps to deduce fields of knowledge and skills that would represent the best the interests of the learners and integrate its output into an enriched learner profile intended for personalized recommendation.

Learner model generation phase. To contain the multiple sources of the data collection phase and enable the dynamic update of the learner model and the offered MOOCs metadata, we chose the ontology-based modeling as an approach for data structuring. Hence, a "Learning Actor ontology" is created as a domain ontology to only model the necessary data for the similarity calculations of the MOOC recommender system. It was developed by following the phases of the on-to-knowledge methodology and distinguishes between domain dependent and domain independent data of learners and MOOCs.

Recommender Suggestions' generation phase. For upcoming development of our research, the personalized recommender model needs to address the weight of each MOOC personalization criteria and an effective use of semantic similarity measures. Nonetheless, the issue of natural language processing that takes place in the data collection phase is expected to influence the accuracy of the suggestions, though deep learning algorithms could be considered to train the recommender engine and ultimately obtain better suggestions.

\section{Conclusion}

Semantic recommender systems rely on the characteristics of learners as a knowledge source to predict the most suitable MOOCs for the learner's preferences and needs. On its basis, our research proposes a functional architecture of a personalized MOOC recommender that takes into consideration the abundance of MOOCs on different platforms and the diversity of the learner's needs that is not necessarily diagnosed by these platforms. Hence, the suggested MOOC recommender is based on three layers. The first layer is the user layer, where each recommendation actor provides the needed data for the data collection phase. As for the second layer, it is the semantic layer where the collected data is structured to provide the learner model and the MOOC model, e.g. the specific domain ontologies of the learning actor metaontology. The last layer is the intelligence layer, where the recommender makes predictions based on the semantic weight learner characteristics compared to potentially interesting MOOCs. Its purpose is to give an intelligent feedback to learners as soon as they access the RS platform and update its outcome according to the learner model update.

At last, the perspective of the development of adapted machine learning algorithms is yet to be studied in future works in order to define the importance weight of each recommendation criteria for the recommendation model. 


\section{$5 \quad$ References}

[1] Amaadid et al., (2017). Conception et réalisation d'un moteur de recommandation à base des données implicites: Cas du service documentaire de la BNRM. Unpublished Master's thesis. Rabat : Ecole des Sciences de l'Information.

[2] Buder, J. and Schwind, C., (2012). Learning with personalized recommender systems: a psychological view. Computers in Human Behavior, 28(1): pp. 207-216. https://doi.org/10.1016/j.chb.2011.09.002

[3] Tarus J. K.et al., (2018). Knowledge-based recommendation: a review of ontology-based recommender systems for e-learning. Artificial Intelligence Review, 50 (1): pp 21-48. https://doi.org/10.1007/s10462-017-9539-5

[4] Béchet N., (2011). Etat de l'art sur les systèmes de recommandations. [pdf] Projet AxIS de l'INRIA, dans le cadre du projet Addictrip ; 2011. Available at: http://people.irisa.fr/Nicolas.Bechet/Publications/EtatArt.pdf [Accessed 14 March 2020]

[5] Lampropoulo, A. S. and Tsihrintzis, G.A., (2015). Machine Learning Paradigms: Applications in Recommender Systems. Intelligent Systems Reference Library, 92. Switzerland: Springer International Publishing. https://doi.org/10.1007/978-3-319-19135-5

[6] Manouselis N. et al., (2013). Recommender Systems for Learning. Springer Briefs in Electrical and Computer Engineering. New York: Springer, New York. https://doi.org/10.1007/978-1-4614-4361-2 1

[7] Burke, R., (2007). Hybrid Web Recommender Systems. In : Brusilovsky, P., Kobsa, A., and Nejdl, W. (Eds.). LNCS 4321: The Adaptive Web, pp. 377-408 Berlin Heidelberg: Springer-Verlag. https://doi.org/10.1007/978-3-540-72079-9

[8] Sharma, R. and Sing, R., (2016). Evolution of Recommender Systems from Ancient Times to Modern Era: A Survey. Indian Journal of Science and Technology, 9 (20), pp. 1-12. Available at: https://www.semanticscholar.org/paper/Evolution-of-Recommender-Systemsfrom-Ancient-Times-Sharma-Singh/e50c7c332b17dc608dfcbbe192d54f1f993647c1 [Accessed 14 March 2020]

[9] Lamharhar, H., Chiadmi, D., Benhlima, L., (2015). Ontology-based knowledge representation for e-Government domain. Paper presented at: iiWAS '15, December 11-13. Brussels, Belgium. http://dx.doi.org/10.1145/2837185.2837203

[10] Vesin, B. et al., (2012). Protus 2.0: Ontology-based semantic recommendation in programming tutoring system. Expert Systems with Applications, 39, pp. 12229-12246. https://doi.org/10.1016/j.eswa.2012.04.052

[11] Cantador, I. et al., (2008). A multilayer ontology-based hybrid recommendation model. AI Communications, 21, pp. 203-210. Available at: https://content.iospress.com/articles/aicommunications/aic437 [Accessed 14 March 2020]

[12] Zhuhadar, L. et al., (2015). Semantically enriched Massive Open Online Courses (MOOCs) platform. Computers in Human Behavior, 51, pp. 578-593. https://doi.org/10.1016/j.chb.2015.02.067

[13] Yu, Z. et al., (2007). Ontology-based semantic recommendation for context- aware E-learning. Lecture notes in computer science, 4611: pp. 898-907. https://doi.org/10.1007/978-3540-73549-6 88

[14] Biletskiy, Y. et al., (2009). An adjustable personalization of search and delivery of learning objects to learners. Expert Systems with Applications, 36 (5). pp. 9113-9120. https://doi.org/10.1016/j.eswa.2008.12.038

[15] Broisin, J. et al., (2010). A Personalized Recommendation Framework based on CAM and Document Annotations. Procedia Computer Science, 1, pp. 2839-2848. https://doi.org/10.1016/j.procs.2010.08.009 
Paper-A Semantic Recommendation System for Learning Personalization in Massive Open Online...

[16] Huang, C. et al., (2011). Semantic Web Enabled Personalized Recommendation for Learning Paths and Experiences. In Zhu, M. (Ed.). Communications in Computer and Information Science, 235, pp. 258-267. Berlin Heidelberg: Springer-Verlag. https://doi.org/10.1007/9783-642-24022-5_43

[17] Shishehchi, S. et al., (2012). Ontological Approach in Knowledge Based Recommender System to Develop the Quality of E-learning System. Australian Journal of Basic and Applied Sciences, 6(2), pp. 115-123

[18] Pukkhem, N., (2014). LORecommendNet: An Ontology-Based Representation of Learning Object Recommendation. In Boonkrong, S. et al. (eds.). Recent Advances in Information and Communication Technology: Advances in Intelligent Systems and Computing, 265, pp.293-303. Switzerland: Springer International Publishing. https://doi.org/10.1007/978-3319-06538-0_29

[19] Pukkhem, N., (2013). Ontology-based Semantic Approach for Learning Object Recommendation. ACEEE Int. J. on Information Technology, 3(4), pp.12-21. Available at: https://pdfs.semanticscholar.org/044e/39932fd72618bbdee5ebb0c4959eb041b2fa.pdf [Accessed 14 March 2020]

[20] Tarus, J.K. et al.., (2017). A hybrid knowledge-based recommender system for e-learning based on ontology and sequential pattern mining. Future Generation Computer Systems, 72 (July): pp. 37-48. https://doi.org/10.1016/j.future.2017.02.049

[21] Isinkaye, F. O. et al., (2015). Recommendation systems: Principles, methods and evaluation. Egyptian Informatics Journal, 16 (3), pp. 261-273. https://doi.org/10.1016/j.eij.2015.06.005

\section{Authors}

Sara Assami received her master's degree in information sciences from the Information Sciences School (ESI) and is currently a PhD student at the Smart Systems Laboratory, of the National Superior School of Computer Science and Systems Analysis (ENSIAS), Avenue Mohammed Ben Abdallah Regragui, Madinat Al Irfane, BP 713, Agdal, Rabat, Morocco (saraassami@gmail.com).

Najima Daoudi is a Professor at the School of Information Sciences, Avenue Ibn sina B.P. 765 Agdal, Rabat, Morocco. She is an Engineer of the National Institute of Statistics and Applied Economics and has a PhD in Computer Science from ENSIAS (daoudinajima@yahoo.fr).

Rachida Ajhoun is a Professor of Higher Education at the Mohammed V University of Rabat, specifically at the ENSIAS, Avenue Mohammed Ben Abdallah Regragui, Madinat Al Irfane, BP 713, Agdal, Rabat, Morocco. She has a PhD degree in Computer Science and E-learning from the Mohammadia School of Engineers, Morocco (r.ajhoun@um5s.net.ma).

Article submitted 2020-02-14. Resubmitted 2020-03-19. Final acceptance 2020-03-20. Final version published as submitted by the authors. 